\title{
A CLINICO-HISTOPATHOLOGICAL STUDY OF ORBITAL AND OCULAR LESIONS; A MULTICENTER STUDY
}

\author{
P Bastola ${ }^{1}$, S Koirala ${ }^{2}$, G Pokhrel ${ }^{3}$, P Ghimire ${ }^{4}$, RK Adhikari ${ }^{5}$ \\ ${ }^{1}$ Department of Ophthalmology, Nepalgunj Medical College and Teaching Hospital, Nepal. \\ ${ }^{2}$ Department of Medicine, National Academy of Medical Sciences, Kathmandu, Nepal. \\ ${ }^{3}$ Department of Ophthalmology, Nepalgunj Medical College and Teaching Hospital, Nepal. \\ ${ }^{4}$ Department of Pathology, Nepalgunj Medical College and Teaching Hospital, Nepalgunj, Nepal. \\ ${ }^{5}$ Department of Ophthalmology, Chitwan Medical College, Bharatpur-10, Chitwan, Nepal. \\ *Correspondence to : Dr Pradeep Bastola, Medical Director, Nepalgunj Eye Hospital, Nepal, \\ Plastic-Oculoplastic and cosmetic facial surgeon.Email: pbs_dinku@yahoo.com
}

\begin{abstract}
The study aimed at finding out the morphological and clinico-pathological correlation of Orbital and Ophthalmic lesions in various eye institutes of Nepal. The study also aimed at finding out the prevalence of Ophthalmic lesions needing histopathological examination. This cross sectional descriptive study was carried out in various tertiary eye hospitals of Nepal from 2008 - 2012. The department of pathology was also incorporated in giving the correct histopathological findings in time. All the relevant data were entered in a specifically designed proforma for the study and analyzed. One hundred Ophthalmic and Orbital lesions were studied in various age groups. Ophthalmic and Orbital lesions were highest (18\%) in 31-40 year age group patients. Eyelid (57\%) was the most commonly involved site. Clinical diagnosis was consistent with histopathological diagnosis in more than $60 \%$ of the cases. Among eyelid lesions, incidence of dermoid cyst (21\%) was highest. While in Conjunctival lesions, granuloma pyogenicum (22.5\%) was highest followed by other lesions. A clinico-pathological diagnosis of malignant orbital tumors or ocular tumors was made in $30 \%$ of cases. While $70 \%$ cases of Ophthalmic or orbital lesions were benign in nature. All Ophthalmic lesions removed surgically should always (without exception) be subjected to histopathological examination to establish correct diagnosis for further management. However this study has shown that a good clinical examination and diagnosis before subjecting the patient for histopathological examination gives the patient and the treating surgeon a better outcome.
\end{abstract}

Key Words: Eyelid, Histopathology, Ocular tumors, Orbital lesions \& Malignant lesions.

\section{INTRODUCTION}

Ophthalmic lesions more precisely; orbital and ocular tumors or tumor like lesions require surgical treatment mostly, hence a correct preoperative provisional diagnosis followed by series of investigations and clinical examination and confirmation of the same by doing histopathological examination of the specimen plays an enormous role in treating both benign and malignant ocular and orbital lesions in patient care. ${ }^{1}$

Ophthalmic histology techniques differ from those of normal tissue in fixation, processing and sectioning. Most anatomical pathology laboratories do not have necessary set up to provide these special techniques. Again it is required to train the personnel to identify disease processes unique to eye diseases or demonstrate them on a microscopic slide along with the pupil and optic nerve. ${ }^{1}$ Ophthalmic Pathology is a subspecialty of Pathology and Ophthalmology that focuses on diseases of the eye, orbit and its neighbouring tissues. Ophthalmic Pathologists study tissues excised by Ophthalmologists to provide a precise diagnosis of the disease. The diseased tissue is examined macroscopically (gross examination) and by light microscopy. Other techniques, such as transmission and scanning electron microscopy, immune histochemistry, as well as molecular biological and other methods are also sometimes employed. ${ }^{2}$

The goal of the Ophthalmic pathology service is to enhance communication between the ophthalmic surgeon and the pathology laboratories and to provide detailed histopathological information that can be correlated with patient history and other clinical data. In this way, histopathological studies have the greatest benefit to ongoing patient care. ${ }^{3}$ Objectives of this study were to study the morphological and clinico-pathological correlation of Ophthalmic lesions, to know the pattern of prevalence of Ophthalmic lesions in various tertiary eye hospitals of Nepal, to find out the accuracy of clinical diagnosis before going for surgical treatment and to compare it with similar studies elsewhere. 


\section{MATERIAL AND METHODS}

A multicentered hospital based study was carried out from January, 2008 to January, 2012 in various tertiary eye hospitals of Nepal. This study was a descriptive, cross-sectional study; however numbers of patients were followed up prospectively. The department of Ophthalmology of the study hospitals Lumbini Eye Institute, Palpa Lions Lacoul Eye Hospital, Nepalgunj Medical College and Nepalgunj Eye Hospitals, Nepal are tertiary eye care centres and they provide a tertiary care for Oculoplastic services including orbital and ocular lesions. All these hospitals have a good support and incorporation of pathologist for histopathological diagnosis with modern laboratory facilities available.

The study strictly adhered to the Tenets of the Declaration of Helsinki and was also approved by the research committee of all hospitals involved.

The cases which were already clinically diagnosed elsewhere, who have already undergone histopathological examination, cases not willing to be part of the study and cases losing follow up or not willing to undergo histopathological examination were excluded from the study.

An informed consent was taken from all the study subjects. A total of 100 cases; after exclusion based on the above mentioned exclusion criteria were taken up for the study purpose. All the cases were evaluated in Oculoplastic, cornea and external disease and when needed in retina clinic over a period of four years. A detailed history taking including systemic illnesses too was done; history taking was followed by a detailed ocular examination. A provisional clinical diagnosis was made in all the cases. To further support the clinical diagnosis various investigations like computed tomography (CT) scan, magnetic resonance imaging (MRI), X-Ray, blood investigations, thyroid hormone levels tests etc were done. After doing needed investigations a final clinical diagnosis was made and was entered in the proforma made for the study.

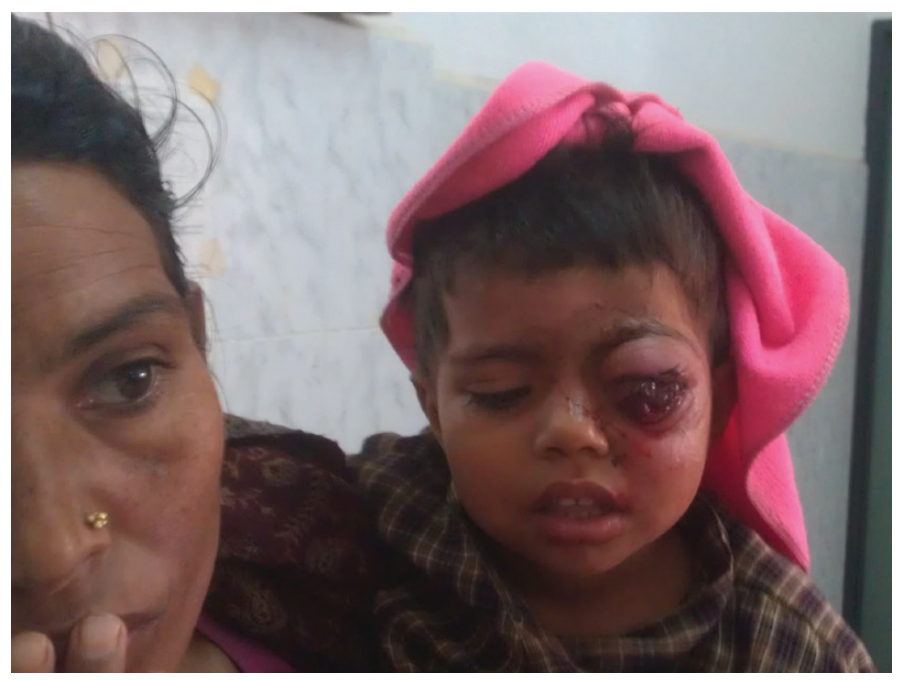

Figure 1: showing a clinically diagnosed case of bilateral retinoblastoma with extra- ocular extension in the Left Eye (Photograph reproduced by taking an informed consent).
Post making the clinical diagnosis (Figure 1) all study subjects were taken up for surgery which included either excision and biopsy or incisional biopsy. The surgically resected specimens fixed in the $10 \%$ formalin were sent to the department of Pathology for histopathological diagnosis. In the department of Pathology, thorough gross examination of each mass for its size, shape, and consistency was done. Several representative areas of tissue were taken from received surgical specimen \& subjected to routine paraffin embedding. Four to five sections $2-3 \mathrm{~mm}$ thick were taken from different areas of specimen $\&$ processed in automatic tissue processor. Blocks were prepared with the help of leuckhart's piece. After trimming of blocks, sections 5-7 um thick were cut with help of automated microtome. Sections were floated on water at temperature of 45 degree \& were taken on aluminized slides. The sections were stained by haematoxylin $\&$ eosin stain in all cases. Special stain such as PAS stain was used whenever required. A histopathological diagnosis thus made available (Figure 2) was entered in the proforma.

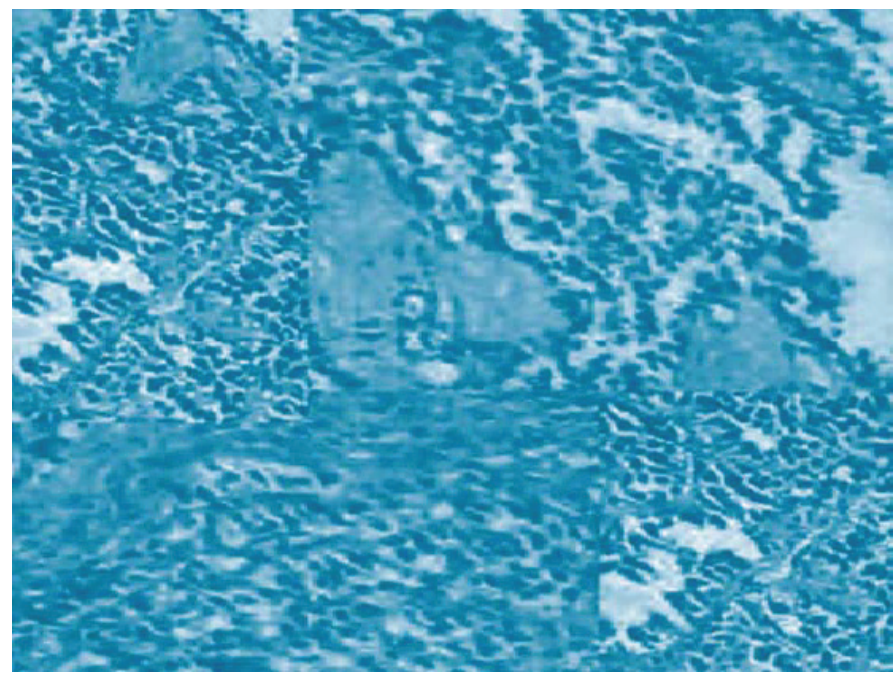

Figure 2: Showing typical histological features of Rhabdomyosarcoma alveolar type; when incised specimen was subjected for histological examination.

Patient care and further management was planned accordingly. All positive and relevant findings of study subjects were entered in a specially designed proforma and analyzed using statistical package for social sciences (SPSS) data version 19.0 and Microsoft office Excel; then the results were interpreted.

\section{RESULTS}

Total 100 cases of ophthalmic lesions were observed. It was found that ophthalmic lesions were highest 18 (18\%) in 31-40 year age group and lowest; one (1\%) in the age group 81-90. After 10 years of age, proportion of lesions increases up to 40 years of age and then declined in each decade afterwards. Sex wise there was not much difference as lesions were found in $49 \%$ females and $51 \%$ males. But in the age group of $31-40$ and 41-50 years proportions were found higher in females $(10 \%)$ compared to males $(6-8 \%)$. While male preponderance $(11 \%)$ was found in 21-30 years of age group (Table 1). 
Table 1: Showing distribution of cases in different genders and various age groups.

\begin{tabular}{|l|c|c|c|}
\hline $\begin{array}{l}\text { Age Group } \\
\text { (Years) }\end{array}$ & Female (N*) & Male (N*) & $\begin{array}{c}\text { Total } \\
\text { Patients } \\
(\mathbf{N})\end{array}$ \\
\hline $1-10$ & $06(11.8 \%)$ & $09(17.6 \%)$ & 15 \\
\hline $11-20$ & $06(11.8 \%)$ & $04(8.2 \%)$ & 10 \\
\hline $21-30$ & $02(3.9 \%)$ & $11(22.4 \%)$ & 13 \\
\hline $31-40$ & $10(19.6 \%)$ & $08(16.3 \%)$ & 18 \\
\hline $41-50$ & $10(19.6 \%)$ & $06(12.2 \%)$ & 16 \\
\hline $51-60$ & $09(17.6 \%)$ & $04(8.2 \%)$ & 13 \\
\hline $61-70$ & $06(11.8 \%)$ & $04(8.2 \%)$ & 10 \\
\hline $71-80$ & $02(3.9 \%)$ & $02(4.1 \%)$ & 04 \\
\hline $81-90$ & 00 & $01(2.0 \%)$ & 01 \\
\hline Total & $\mathbf{5 1 ( 1 0 0 \% )}$ & $\mathbf{4 9}(\mathbf{4 9 \%})$ & $\mathbf{1 0 0}(\mathbf{1 0 0 \% )}$ \\
\hline
\end{tabular}

$*=$ Number of patients

$\dagger=$ Various age groups in the study subjects

From malignancy point of view, lesions were benign in $70(70 \%)$ cases and malignant in 30\% cases. Location wise; eyelid (57\%) was the most commonly involved site followed by conjunctiva $(22 \%)$ and orbit $(8 \%)$, while lacrimal sac $(2 \%)$ was the least commonly involved site (Table 2). Clinical diagnosis was consistent with histopathological diagnosis in approximately 65 study subjects $(65 \%)$.

Table 2: Showing the location of the lesions with regard to number of patients

\begin{tabular}{|l|c|}
\hline Location $\dagger$ & $\mathbf{N * ( \% )}$ \\
\hline Eyelids & $57(57 \%)$ \\
\hline Conjunctiva & $22(22 \%)$ \\
\hline Orbit & $8(8 \%)$ \\
\hline Lacrimal gland & $6(6 \%)$ \\
\hline Retina & $5(5 \%)$ \\
\hline Lacrimal Sac & $2(2 \%)$ \\
\hline
\end{tabular}

$*=$ Number of patients

$\dagger=$ Showing the location of the lesions in the study subjects.
Among eyelid lesions, dermoid cyst (21\%) was highest followed by epidermal inclusion cyst (14\%), intradermal nevus $(12.2 \%)$ and sebaceous (meibomian) carcinoma (8.7\%) (Table 3).

Table 3: Showing different types of eyelid lesions diagnosed in the study subjects.

\begin{tabular}{|l|c|}
\hline Eyelid Lesions $\dagger$ (N*57) & Total cases (\%) \\
\hline Dermoid cyst + & $12(21.0 \%)$ \\
\hline Epidermal inclusion cyst & $8(14.0 \%)$ \\
\hline Intradermal Nevus & $7(12.2 \%)$ \\
\hline Sebaceous (meibomian) carcinoma & $5(8.7 \%)$ \\
\hline Capillary haemangioma & $4(7.0 \%)$ \\
\hline Cavernous haemangioma & $3(3.5 \%)$ \\
\hline Fibroepithelial polyp & $2(3.5 \%)$ \\
\hline Seborrheic keratosis & $2(3.5 \%)$ \\
\hline Eccrine hydrocystoma & $2(3.5 \%)$ \\
\hline Malignant melanoma & $2(3.5 \%)$ \\
\hline Pigmented basal cell carcinoma & $2(3.5 \%)$ \\
\hline Adenoid basal cell carcinoma & $1(1.7 \%)$ \\
\hline Neurofibroma & $1(1.7 \%)$ \\
\hline Moderately differential squamous cell \\
carcinoma
\end{tabular}

$*=$ Total number of eyelid lesions only.

$\uparrow=$ Showing various different types of eyelid lesions diagnosed $t=$ Showing the highest prevalence of dermoid cyst amongst eyelid lesions.

Among conjunctival lesions, granuloma pyogenicum $(22.5 \%)$ was highest followed by capillary haemangioma $(13.5 \%)$ (Table 4). 
Table 4: Showing the prevalence of various types of diagnosed conjunctival lesions.

\begin{tabular}{|l|l|}
\hline Diagnosed cases of conjunctival lesions $\dagger$ & $\begin{array}{l}\text { Lesions } \\
\left(\mathbf{N}^{*}=\mathbf{2 2}\right)\end{array}$ \\
\hline Granuloma Pyogenicum + & $5(22.5 \%)$ \\
\hline Capillary haemangioma & $3(13.5 \%)$ \\
\hline Conjunctival papilloma & $2(9.0 \%)$ \\
\hline Epidermal inclusion cyst & $2(9.0 \%)$ \\
\hline Squamous cell carcinoma & $2(9.0 \%)$ \\
\hline Well differentiated Squamous cell carcinoma & $2(9.0 \%)$ \\
\hline Choriostomas & $1(4.5 \%)$ \\
\hline Cavernous haemangioma & $1(4.5 \%)$ \\
\hline Compound nevus & $1(4.5 \%)$ \\
\hline Orbital fat prolapsed & $1(4.5 \%)$ \\
\hline Conjuctival cyst & $1(4.5 \%)$ \\
\hline Moderately differentiated Squamous cell & $1(4.5 \%)$ \\
\hline
\end{tabular}

$*=$ Total number of conjunctival lesions.

$\dagger=$ Various types of diagnosed conjunctival lesions.

$\$=$ Commonest diagnosed lesion amongst conjunctival lesions.

Amongst various orbital lesions Non Hodgkin's lymphoma was the commonest followed by orbital rhabodomyosarcoma (Table $5)$.

Table 5: Showing prevalence of various orbital lesions.

\begin{tabular}{|l|c|}
\hline Orbital Lesions $\dagger$ & $\mathbf{N}^{*}$ \\
\hline Non Hodgkin's Lymphoma & $3(37.5 \%)$ \\
\hline Cavernous Haemangioma & $1(12.5 \%)$ \\
\hline Mucocele & $1(12.5 \%)$ \\
\hline Schwannoma & $1(12.5 \%)$ \\
\hline Alveolar Rhabdomyosarcoma & $1(12.5 \%)$ \\
\hline Embroyonal Rhabdomyosarcoma & $1(12.5 \%)$ \\
\hline
\end{tabular}

$*=$ Total number of orbital lesions.

$\uparrow=$ Various types of diagnosed orbital lesions.

\section{DISCUSSION}

Results of the present study were comparable with various other similar studies. Note worthy; the results of present study are comparable with the study carried out by Ud Din $\mathrm{N}$ et al. ${ }^{4}$ In our study, benign lesions were $70 \%$ while malignant lesions were $30 \%$, while similar study conducted was quite similar to the present study, in which the prevalence of benign and malignant lesions were found it $61.5 \%$ and $38.5 \%$ respectively. ${ }^{4}$ The most striking feature is bimodal peak seen in our study which is same as the study carried out by Ud-Din $\mathrm{N}$ et al. ${ }^{4}$ Like Ud-Din $\mathrm{N}$ et al study, most common malignancy in children in present study was also retinoblastoma. Which in any case is the commonest primary intraocular malignancy in the children.

Regarding sex wise distribution in malignant ophthalmic tumour, in present study $53.3 \%$ were males and $46.7 \%$ were females. Thakur SK et al ${ }^{5}$ reported $51.2 \%$ males and 48 $.8 \%$ females. While Sunderraj $\mathrm{P}^{6}$ observed $56 \%$ males and $44 \%$ females. Frequency among children was $18 \%$ in present study while Tikur Anbessa et al ${ }^{7}$ found it 20\% which was almost similar to this study. Frequency of retinoblastoma in our study was $27.5 \%$ which were less compared to other study. ${ }^{7}(39 \%)$. Clinical accuracy was decided on the basis where clinical diagnosis matches with histopathological diagnosis. In our study clinical accuracy was in almost (65\%) cases, while other studies ${ }^{8,10}$ found it on higher side as it was $84 \%, 91.5 \%$ and $96 \%$. These comparisons are clearly emphasizing on need for biopsy of all surgically removed specimens so that a definitive diagnosis is made and hence treatment thereafter in needy cases.

Prevalence of benign and malignant lesions of conjunctival tumors in present study was $79 \%$ and $21 \%$ respectively. The same was observed in other study ${ }^{11}$ as they were $78.5 \%$ and $21.5 \%$ respectively. In the study of Obata $\mathrm{H} \mathrm{et} \mathrm{al}{ }^{11}$ most common benign lesion was intradermal nevus(13\%). While in our study most common benign lesion were granuloma pyogenicum $(22.5 \%)$ followed by intradermal nevus $(4.5 \%)$. In the study of Obata $\mathrm{H}$ et al most common malignant lesion was malignant lymphoma (9\%). While in our study most common malignant lesion was squamous cell carcinoma (22.5\%). Among eyelid malignancy, present study found $41.7 \%$ sebaceous (meibomian) carcinoma and $33.3 \%$ basal cell carcinoma. ${ }^{11}$ While study carried out by Jahagirdar SS et al, observed 37\% sebaceous (meibomian) carcinoma and $44 \%$ basal cell carcinoma. ${ }^{12}$

Table 6 shows that results of present study are comparable with the study carried out by Obata $\mathrm{H}$ et al study, Abdi $\mathrm{U}$ et al study, Tesluk GC et al study. ${ }^{11,13,14}$ In the study of Obata $\mathrm{H}$ et al 11 most common benign lesion was intradermal nevus $(21.3 \%)$. While in our study most common benign lesion was dermoid cyst $(21 \%)$, while intradermal nevus $(12.2 \%)$.In the study of Obata $\mathrm{H}$ et al; most common malignant lesion was sebaceous (meibomian) carcinoma (15\%).In our study also the most common malignant lesion was sebaceous (meibomian) carcinoma $(8.7 \%)$. In the study of Abdi $U$ et al ${ }^{13}$ most common benign lesion was vascular tumour $(21.3 \%)$. While in our study most common benign lesion were dermoid cyst $(21 \%)$ followed by intradermal nevus (12.2\%). In the study of Abdi U 
et al ${ }^{13}$ most common malignant lesion was basal cell carcinoma (38.8) while in our study most common malignant lesion was sebaceous (meibomian) carcinoma (8.7\%). In the study of Tesluk GC et al ${ }^{14}$ the most common lesion of the eyelid was basal cell carcinoma, which represented $14.3 \%$ of the total and $82.4 \%$ of the malignant lesions while in our study; most common malignant lesion is sebaceous (meibomian) carcinoma $(8.7 \%)$.

Table 6: Showing Comparison of Incidence of benign and malignant lesions of eyelid tumors in various studies. ${ }^{11,13,14}$ with present study.

\begin{tabular}{|l|l|l|}
\hline Name of study (Eyelid lesions $\dagger$ ) & Benign & Malignant \\
\hline Obata H et al study. 2005 & $73 \%$ & $27 \%$ \\
\hline Abdu U et al study, 1996 & $58.90 \%$ & $41.10 \%$ \\
\hline Tesluk GC et al. 1984 & 82.60 & $17.40 \%$ \\
\hline Present study; 2013 & $\mathbf{7 9 \%}$ & $\mathbf{2 1 \%} \%$ \\
\hline
\end{tabular}

$\dagger=$ Showing the comparision of occurrence of different eyelid tumors in various studies and comparing it with the present study.

In summary, we can conclude that all ophthalmic lesions removed surgically should always be subjected to histopathological examination to establish correct diagnosis for further management.

\section{CONCLUSIONS}

The study concluded that a histopathological examination of excised or incised orbital or ocular lesions are absolutely mandatory for each case to come to a definitive diagnosis and further care of patients in management. However; we cannot deny the fact that clinical diagnosis does play a very important role in going towards a right direction in treating cases and curing them.

\section{ACKNOWLEDGEMENTS}

We would like to acknowledge all the patients their caretakers for the support they provided during the study. We would like to pass a special debt to Mrs. Sheela Bastola for making sure all the data are entered in time and finally would like to thank everybody who directly or indirectly supported this study to get concluded.

\section{REFERENCES}

1. Histology of eye. Available from: http://ophthapg. blogspot. com/2008/12/histology-of-eye.html. Accessed January, 2012.

2. Ophthalmic Pathology Primer. Available from: http// www.vetmed.ucdavis.edu/courses/vet_eyes/eye_path/epath overview_index html. Accessed January, 2012.

3. Ophthalmic Pathology Service. Available from: http// www.smbs.buffalo.edu/ophthalmology/clinical Services/ pathology_fed.html. Accessed January, 2012

4. Ud-Din N, Mushtaq S, Mamoon N, Khan AH, Malik IA. , Morphological spectrum of ophthalmic tumors in northern Pakistan. J Pak Med Assoc. 2001 Jan; 51(1):19-22.

5. Thakur SK, Sah SP, Lakhey M, Badhu BP. Primary malignant tumours of eye and adnexa in Eastern Nepal. Clin Experiment Ophthalmo 2003 Oct; 31(5):415-7.

6. Sunderraj P. Malignant tumours of the eye and adnexa. Indian J Ophthalmol 1991 Jan-Mar;39(1):6-8.

7. Tikur Anbessa, Menelik. Pattern of ophthalmic lesions at two histopathology centres in Ethiopia. East Afr Med J 2001 May; 78(5):250-4.

8. Kersten RC, Ewing- Chow D, Kulwin DR, Gallon M. Accuracy of clinical diagnosis of cutaneous eyelid lesions. Ophthalmology 1998 Feb; 105(2):203-4.

9. Deokule S, Child V, Tarin S, Sandramouli S. Diagnosticaccuracy of benign eyelid skin lesions in the minor operation theatre. Orbit 2003 Dec; 22(4):235-8.

10. Margo CE. Eyelid tumors: accuracy of clinical diagnosis. Am J Ophthalmol 1999 Nov; 128(5):635-6.

11. Obata H, Aoki Y, Kubota S, Kanai N, Tsuru T, Incidence of benign and malignant lesions of eyelid and conjunctival tumors. Nippon Ganka Gakkai Zasshi 2005 Sep; 109(9):573-9.

12. Jahagirdar SS, Thakre TP, Kale SM, Kulkarni H, Mamtani M. A clinicopathological study of eyelid malignancies from central India. Indian J Ophthalmol 2007 Mar-Apr; 55(2):10912.

13. Abdi U, Tyagi N, Maheshwari V, Gogi R, Tyagi SP. Tumours of eyelid: a clinico- pathologic study. J Indian Med Assoc 1996 Nov; 94(11):405-9.

14. Tesluk GC. Eyelid lesions: incidence and comparison of benign and malignant lesions. Ann Ophthalmol 1985 Nov; 17(11):704-7. 